\title{
INFLUENCE OF LOADING RATE ON THE MATERIAL DEFORMATION BEHAVIOUR UNDER BI-AXIAL LOADING
}

\author{
${ }^{1}$ Pavel SOLFRONK, ' Jiří SOBOTKA, 'David KOREČEK, 'David MIZERA \\ ${ }^{1} T U L$ - Technical University of Liberec, Liberec, Czech Republic, EU, \\ pavel.solfonk@tul.cz, iiri.sobotka@tul.cz, david.korecek@tul.cz, david.mizera@tul.cz
}

https://doi.org/10.37904/metal.2020.3478

\begin{abstract}
In recent years, great effort has been made in all branches of industries to put into practise new methods and procedures using numerical support for technological processes, digitization and robotization of the production operations. The complex of these measures is known as Industry 4.0, which aims to reduce production costs, while increasing the flexibility of companies. The concept of the so-called virtual factory makes possible to predict possible problems and problematic production points already in the design phase by means of the numerical modelling. A prerequisite for the proposed virtual concept functioning is necessity to master the individual partial solutions with the sufficient accuracy of the whole computation with the subsequent data sharing in case of their need in other stages of the virtual solution. With the development of the computer technology (both in hardware and software), there is obvious effort to use still more and more complex mathematical computation models that allow taking into account a higher number of input process parameters and thus to achieve a higher computation accuracy. The paper is focused on the issue of technological processes numerical modelling at thin sheets drawing. As a needed prerequisite for obtaining the result having required accuracy, there is the correct choice of proper deformation model and definition of boundary conditions, which take into account the monitored technological process. In order to define advanced mathematical models of thin steel sheets deformation behaviour, it is necessary to perform (beside standard tests as e.g. static tensile test) also tests under biaxial loading. One of the most common tests for determining mechanical properties under biaxial loading is the hydrostatic bulge test (HBT). In the experimental part, the paper evaluates the influence of loading rates on the resulting mechanical properties of tested material. The required strain rate is affected by the time change of pressure increase. There were used three loading rates with linear pressure increase and two loading rates with holding time to enable stress relaxation of tested material. The contact-less optical system Mercury RT was used for data acquisition and deformation analysis. For the selected test parameters, stress-strain curves were determined from the measured values. Based upon these stress-strain curves, there was subsequently evaluated influence of the strain rate on the deformation behaviour of tested material and stress relaxation during the tests. As a testing material was used deep-drawing material specified for drawing stampings in the automotive industry.
\end{abstract}

Keywords: Stress-strain curves, contact-less deformation measurement, deep-drawing material, stress relaxation

\section{INTRODUCTION}

These days are for the thin sheets metal forming numerical simulations used more and more complex mathematical models of deformation behavior, which are able to describe the relatively complex process of thin sheet metal forming with sufficient accuracy. As one of the most important material parameters in the considered mathematical model, there is transition of the formed material to the plastic state (yield criterion) and subsequent change of mechanical properties due to the material strengthening. In addition to the basic material parameters obtained from the static tensile test, it is in the case of advanced deformation models 
necessary to perform also other tests that take into account the deformation behavior of tested material at multi-axial stress states and also tests, in which the loading direction (tension-compression stress) changes.

The paper deals with the issue of determining material parameters under bi-axial loading by hydrostatic bulge test (so-called hydraulic bulge test - HBT). The methodology of performing and evaluating of this test is sufficiently known and the obtained results are (in addition to the results from the static tensile test) generally considered to be the truly basic mechanical parameters of advanced computational models. The considered stress state within the range from uniaxial to equi-biaxial tension $\left(\sigma_{1}=\sigma_{2}\right)$ represents all stable states of the formed material and also determines the limit states when measuring the forming limit curve (FLC). In the experimental part of this paper, the research about the influence of tested material loading rate on the relevant stress-strain curves during the hydrostatic bulge test is performed. As another monitored issue there is also stress relaxation in the material under equi-biaxial loading. The presented measurement results can be used both for research of thin steel sheets deformation processes and in the field of numerical simulations for reliable definition of advanced computational models.

\section{INFLUENCE OF LOADING RATE ON STRESS-STRAIN CURVE AT HBT}

As a tested material, there was chosen the deep-drawing material HX180BD+Z100MCO of thickness $0.7 \mathrm{~mm}$. It is low-carbon steel that is mainly used in the automotive industry for the car-body outer panels. Basic mechanical properties (measured from 10 samples) of this material are summarized in Table 1, where are given average values $\mathbf{x}$ together with the standard deviation $\mathbf{s}$.

Table 1 Basic mechanical properties of tested deep-drawing material HX180BD+Z100MCO

\begin{tabular}{|c|c|c|c|c|c|c|c|}
\hline \multicolumn{2}{|c|}{$\begin{array}{c}\text { Rolling } \\
\text { direction }\end{array}$} & \multirow{2}{*}{$\begin{array}{c}\begin{array}{c}\text { Upper yield } \\
\text { strength }\end{array} \\
R_{\mathrm{eH}}(\mathrm{MPa}) \\
203\end{array}$} & \multirow{2}{*}{$\begin{array}{c}\begin{array}{c}\text { Lower yield } \\
\text { strength }\end{array} \\
R_{\mathrm{eL}}(\mathrm{MPa}) \\
224\end{array}$} & \multirow{2}{*}{$\begin{array}{c}\begin{array}{c}\text { Ultimate } \\
\text { tensile } \\
\text { strength } \\
R_{\mathrm{m}}(\mathrm{MPa})\end{array} \\
330\end{array}$} & \multirow{2}{*}{$\begin{array}{c}\begin{array}{c}\text { Uniform } \\
\text { ductility }\end{array} \\
\boldsymbol{A}_{\mathrm{g}}(\%) \\
20.7 \\
\end{array}$} & \multirow{2}{*}{$\begin{array}{c}\begin{array}{c}\text { Total } \\
\text { ductility }\end{array} \\
\text { A80mm (\%) } \\
35.9\end{array}$} & \multirow{2}{*}{$\begin{array}{c}\begin{array}{c}\text { Plastic strain } \\
\text { ratio } \\
r(-)\end{array} \\
1.643\end{array}$} \\
\hline 0 & $\mathbf{x}$ & & & & & & \\
\hline & $\mathrm{s}$ & 0.64 & 0.55 & 0.35 & 0.42 & 0.37 & 0.016 \\
\hline \multirow{2}{*}{$45^{\circ}$} & $\mathbf{x}$ & 207 & 227 & 328 & 20.3 & 35.2 & 1.615 \\
\hline & $\mathrm{s}$ & 1.39 & 1.67 & 0.18 & 0.47 & 0.58 & 0.028 \\
\hline \multirow{2}{*}{$90^{\circ}$} & $\mathbf{x}$ & 205 & 220 & 326 & 20.6 & 36.9 & 2.032 \\
\hline & $\mathrm{s}$ & 0.84 & 0.98 & 0.23 & 0.24 & 0.84 & 0.052 \\
\hline
\end{tabular}

To determine the material stress-strain curve under biaxial loading, it was necessary to synchronously acquire the strain values and magnitude of pressure in the fluid (hydraulic pressure) during the test. Own deformation was measured by a contact-less optical system MercuryRT with a pair of synchronized cameras under resolution $5 \mathrm{MPx}$ and scanning frequency as $30 \mathrm{~Hz}$. In addition to the deformation measurement, the system also made possible to determine the shape and dimensions in the scanning area. Relevant value of hydraulic pressure was acquired at the same time with each measured image. The required precise setting of the magnitude and course of pressure increase in the hydraulic system was achieved by the hydraulic servocontrol with PID controller with control loop mechanism employing feedback from pressure sensor located directly in the area of tested sample. Under such experimental "lay-out", achieved accuracy of the required pressure setting is $\pm 0.002 \mathrm{MPa}$. Own scheme of the test arrangement is evident from Figure 1a. To determine the influence of strain rate on the stress-strain curve of tested material, three linear pressure increase rates in the fluid were chosen, namely $0.05 \mathrm{MPa} / \mathrm{s}, 0.15 \mathrm{MPa} / \mathrm{s}$ and $0.3 \mathrm{MPa} / \mathrm{s}$. The criterion for terminating the test was when a pressure achieved magnitude of $7 \mathrm{MPa}$. At given geometrical conditions of testing jig, such value 
of pressure represents the limit value before the crack occurs. To determine the stress-strain curve, it was necessary to calculate the values of effective stress and effective strain. The magnitude of effective stress can be calculated from equation (1), effective strain can be subsequently expressed by equation (2). Thus for own calculation, it is necessary to determine the actual values of major strain for formed sample at given time moment (acc. to scanning frequency), the radius of curvature and hydraulic pressure. All necessary values are simultaneously recorded and then evaluated by PC. The radius of curvature for given sample is calculated by best fit method directly in the software Mercury RT, as it is shown in Figure 1b.

$\sigma_{i}=\sigma_{1}-\frac{\mathrm{p}}{2}=\frac{\mathrm{p} \mathrm{R}_{\mathrm{d}}}{2 \mathrm{t}}-\frac{\mathrm{p}}{2}$

$\varphi_{i}=\frac{\sqrt{12}}{3} \sqrt{\varphi_{1}^{2}+\varphi_{2}^{2}+\varphi_{1} \cdot \varphi_{2}}$

$t=\mathrm{t}_{0} \cdot \mathrm{e}^{\varphi_{3}}$

where:
$\sigma_{1}$ - true stress in the wall of sample
(MPa)
p - hydraulic pressure
(MPa)
$R_{d}$ - sample radius of curvature
(mm)
t - actual thickness of sample
(mm)
to - initial thickness of sample
(mm)
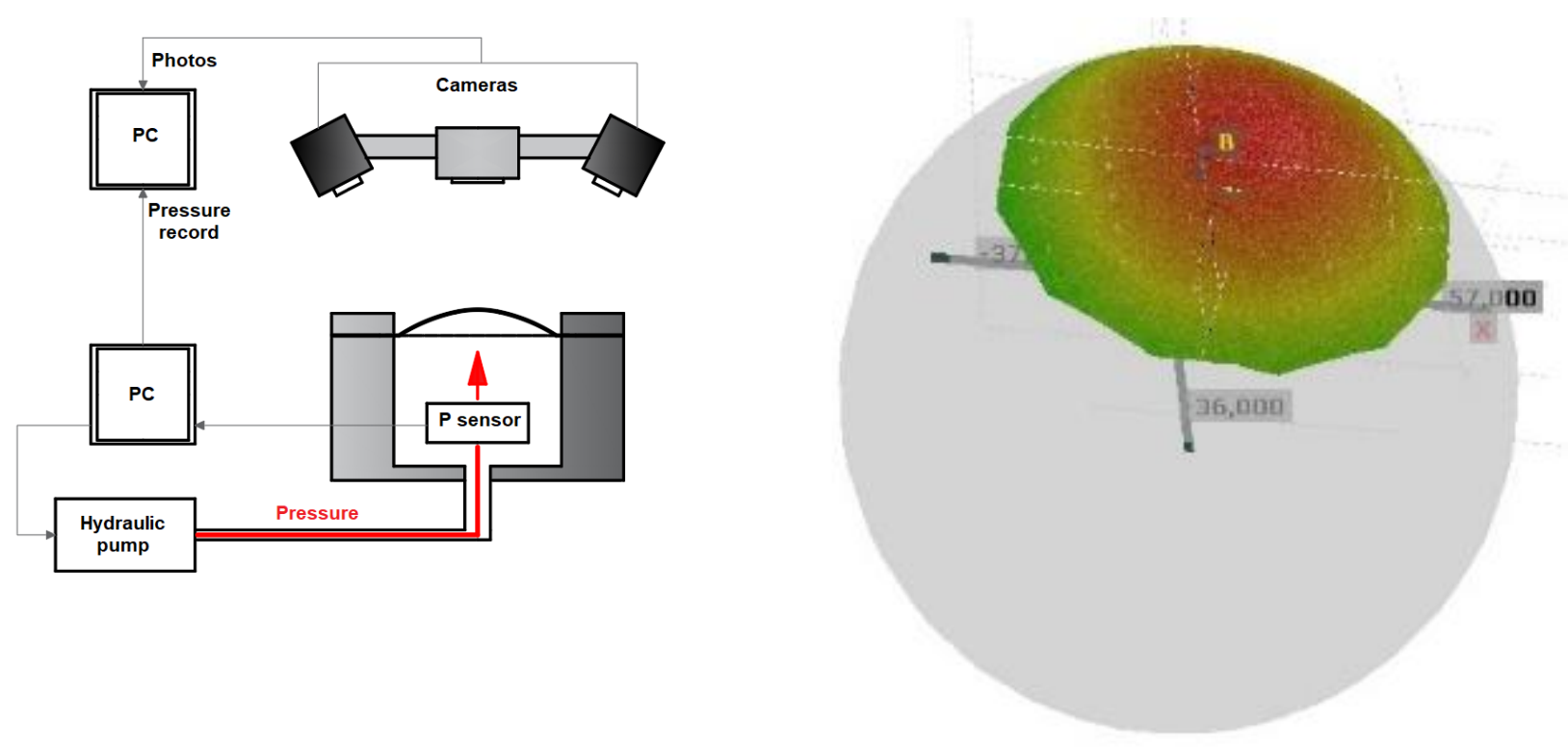

a) Workplace lay-out

b) Sample radius of curvature determination

Figure 1 Principle of the hydrostatic bulge test (HBT)

In this paper, always 6 samples were tested for the selected conditions. Stress-strain curves for the individual pressure increase rates are shown in Figure 2, which graphically shows the average stress-strain curves obtained from that 6 measurements. From the graphical expression it is evident that the pressure increase rate within the tested range of $0.05 \mathrm{MPa} / \mathrm{s}$ to $0.3 \mathrm{MPa} / \mathrm{s}$ has practically no effect on the stress-strain curve of tested material HX180BD + Z100MCO. 


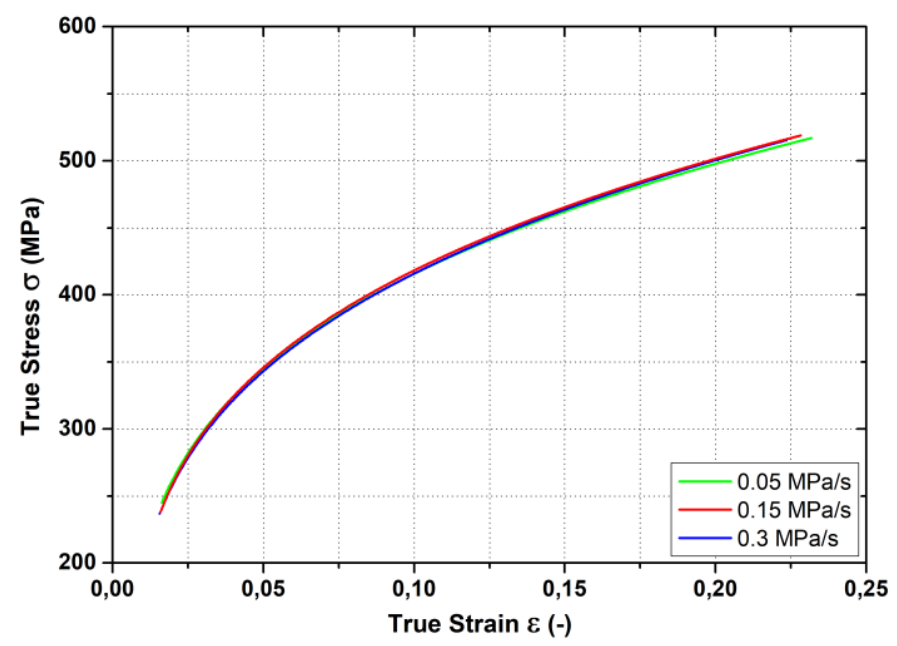

Figure 2 Stress-strain curves for the linear pressure increase rates

\section{INFLUENCE OF STRESS RELAXATION ON THE STRESS-STRAIN CURVE AT HYDRAULIC BULGE TEST}

In the subsequent phase of material deformation behaviour during the hydrostatic bulge test research was determined, whether the measured values of the stress-strain curve will change if the hydraulic pressure doesn't increase linearly (as it was done in the previous case). For the tests was chosen such mode, where hydraulic pressure always increased after discrete values of $0.25 \mathrm{MPa}$ with the holding time $10 \mathrm{sec}$ on this value. The testing mode was adjusted in this manner with respect to the presumption about stress and strain relaxation in the deformed material within that holding time $10 \mathrm{sec}$ at constant hydraulic pressure. In order to achieve the relevant experimental results, it was necessary to technically ensure a very accurate achievement of the required pressure magnitude with subsequent constant holding on this value. As there was already mentioned above, this requirement is fulfilled by using a hydraulic servo-operated valve with PID control and accuracy $\pm 0.002 \mathrm{MPa}$ within the whole tested range of working pressures (up to $7 \mathrm{MPa}$ ). The pressure increase rate between the individual values was adjusted as $0.05 \mathrm{MPa} / \mathrm{s}$. From the graph in Figure 3a is evident method for evaluating data to determine the stress-strain curve at a discrete pressure increase with holding time of $10 \mathrm{~s}$. The red curve indicates such stress-strain curve constructed as connection of points after stress and strain relaxation for time $10 \mathrm{~s}$.

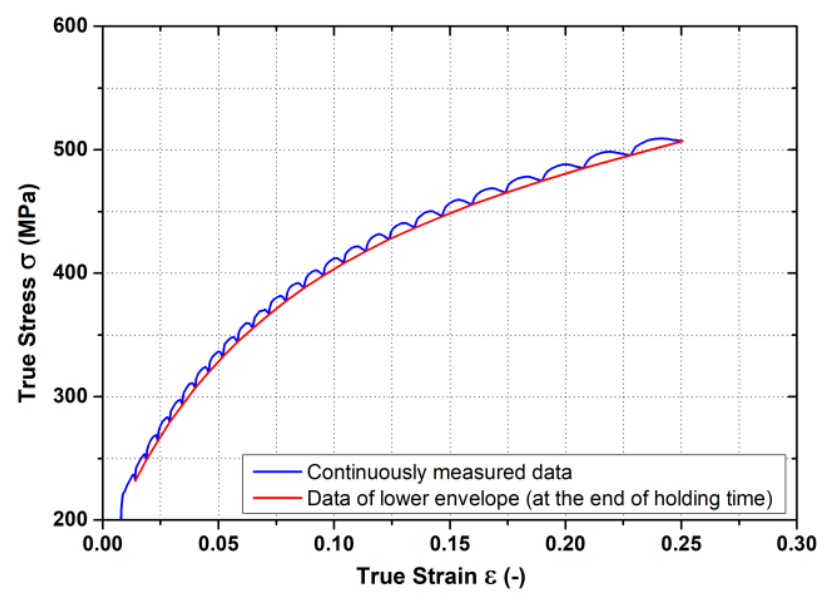

a) Holding time $10 \mathrm{~s}$

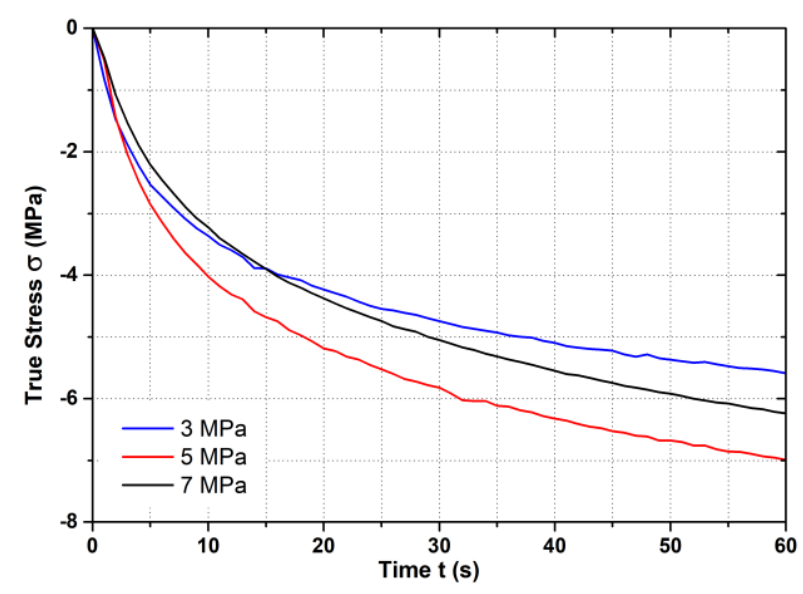

b) Holding time $60 \mathrm{~s}$

Figure 3 Stress relaxation under HBT 
From the graph shown in Figure 3a, it can be seen that during holding time 10 s there is stress relaxation for all used pressures thus also stress-strain curve decreases. To investigate this phenomenon, an experiment was performed in which the stress change (relaxation) of tested sample under a constant pressure load of 3 , 5 and $7 \mathrm{MPa}$ was monitored at holding time of $60 \mathrm{~s}$ for these values. Pressure increase rate to reach the desired value was chosen for all tested holding pressures as $0.05 \mathrm{MPa} / \mathrm{s}$. The stress decrease of tested sample in the monitored time interval ( $60 \mathrm{~s}$ ) is graphically illustrated in Figure $\mathbf{3 b}$. From the course of stress can be seen that time change of stress is the most remarkable at the beginning of holding time and it decreases with increasing time. For the mathematical evaluation of this effect, measured values of the stress change were approximated by the equation (4). Final values of approximation constants for the individual pressures are summarized in Table 2.

$\mathrm{y}=\mathrm{A}^{(\mathrm{x}-\mathrm{B})}-\mathrm{C}$

where: $A, B, C \quad$ - approximation constants

Table 2 Results of approximation constants for relevant pressures

\begin{tabular}{|c|c|c|c|}
\hline \multirow{2}{*}{ Approximation constants } & \multicolumn{3}{|c|}{ Pressure } \\
\cline { 2 - 4 } & $3 \mathrm{MPa}$ & $5 \mathrm{MPa}$ & $\mathrm{MPa}$ \\
\hline $\mathrm{A}\left(\mathrm{MPa}^{1 / \mathrm{s}}\right)$ & 0.9288422 & 0.9332712 & 0.9436955 \\
\hline $\mathrm{B}(\mathrm{s})$ & 20.722041 & 26.145119 & 29.821812 \\
\hline $\mathrm{C}(\mathrm{MPa})$ & 5.4055813 & 6.8004922 & 6.1891903 \\
\hline
\end{tabular}

\section{CONCLUSION}

The hydrostatic bulge test is one of the basic material tests used to numerically define the deformation behavior of materials during the deep drawing. In the specialized literature can be find enough information about the principle of this test and how to evaluate the measured data, along with a presentation of possible utilization of measurement results. However, acc. to the relevant standard, there are not given precise testing conditions, such as e.g. loading rate or application of holding pressures (holding times) under which stress relaxation occurs. In the experimental part of this paper, the effect of the pressure increase rate and stress relaxation on the resulting stress-strain curves of tested deep-drawing material was determined. The analysis of the pressure increase rate effect shows that within the range of the tested loading rates from $0.05 \mathrm{MPa} / \mathrm{s}$ to $0.3 \mathrm{MPa} / \mathrm{s}$, the influence of loading rate on the stress-strain curve shape is insignificant. Minor differences in the shape of curve are technically negligible. Nevertheless, significant effect on the resulting stress-strain curve can be observed in the case of stress relaxation during test at application different holding times. When there was used the test mode, where test was performed with $10 \mathrm{~s}$ holding time at relevant pressures, the stress-strain curve decreases by about $3 \%$ compared to the results obtained with a continuous pressure increase. For this reason, the research was further focused on the stress relaxation and finding the course of stress time change during the test. From the measured experimental results it is evident that the largest stress decrease occurs at the beginning of holding time and own nature of such stress change (relaxation) can be well expressed by the exponential function. The test was also performed for holding time of $60 \mathrm{~s}$, but from the result of this experiment it is evident that the stress relaxation occurs even after this holding time. With regard to the real conditions of forming technologies, when deformation processes last maximally in the order of units of seconds, monitoring the stress relaxation in the material for a period longer than 60 seconds is no relevant. Presented results can be used to increase accuracy of the mathematical models used for technological forming processes numerical modeling, where it is possible to apply relaxation processes of the formed material. These are mainly simulations of technological processes using so-called super-formable materials and hydroforming, where are used extremely small strain rates. 


\section{ACKNOWLEDGEMENTS}

This work was supported by the Student Grant Competition of the Technical University of Liberec under the project No. SGS-2019-5015 "Research and development for innovation of materials and production technologies with application potential in mechanical engineering".

\section{REFERENCES}

[1] WANKHEDE, P., SURESH, K. A review on the evaluation of formability in sheet metal forming. Advances in Materials and Processing Technologies. 2020, vol. 6, no. 2, pp. 402-429. DOI:10.1080/2374068X.2020.1731229

[2] KUHN, H., D. MEDLIN, ed. ASM HANDBOOK Volume 8 - Mechanical Testing and Evaluation. 10th ed. Materials Park: ASM International, 2000. ISBN 0-87170-389-0.

[3] ASHBY, M.F. Materials Selection in Mechanical Design. 3rd ed. Oxford: Butterworth-Heinemann, 2005. ISBN 07506-6168-2.

[4] WU, B., H. WANG, T. TAYLOR a J. YANAGIMOTO. A non-associated constitutive model considering anisotropic hardening for orthotropic anisotropic materials in sheet metal forming. International Journal of Mechanical Sciences [online]. 2020, vol. 169. DOI:10.1016/j.jimecsci.2019.105320

[5] MIRNIA, M.J. a M. VAHDANI. Calibration of ductile fracture criterion from shear to equibiaxial tension using hydraulic bulge test. Journal of Materials Processing Technology [online]. 2020, vol. 280.

DOI:10.1016/j.jmatprotec.2020.116589

[6] COPPIETERS, S., M. JACKEL, C. KRAUS, T. KUWABARA a F. BARLAT. Influence of a hydrostatic pressure shift on the flow stress in sheet metal. In: Procedia Manufacturing [online]. 2020, vol. 47, pp. 1245-1249.

DOI:10.1016/j.promfg.2020.04.196 